\title{
POROSITAS KAYU JATI KLON CEPU DAN MADIUN UMUR 7 TAHUN
}

\author{
Wood Porosity of Seven-Year Old Teak from Cloned Cepu and Cloned Madiun \\ Andi Detti Yunianti ${ }^{\boxplus}$ \\ Lab. Pemanfaatan dan Pengolahan Hasil Hutan, Fakultas Kehutanan Universitas Hasanuddin, \\ Jl. Perintis Kemerdekaan Km. 10 Tamalanrea, Makassar 90245
}

\begin{abstract}
This study was aimed at determining the pore characteristic (type, dimension and frequency of vessel) of teak from different clones (Cloned Cepu and Madiun). For the purpose of the study, teak wood samples with the age of 7 years were taken from research site number 22a of RPH Banaran, BKPH Playen, Gunung Kidul, in Watu Sipat Forests, Biotechnology and Forest Tree Improvement Research Facilities in Yogyakarta at different planting distances $(3 \mathrm{~m}$ $\times 3 \mathrm{~m}$ and $2 \mathrm{~m} \times 6 \mathrm{~m}$ ). Results show that the type of pores is diffuse-porous until the $3^{\text {th }}$ growth ring and after that; it becomes semi ring-porous. The variation of diameter, length and frequency of vessels from cloned Cepu and spacing $3 \mathrm{~m} \times 3 \mathrm{~m}$ are comparatively uniform compared to that of cloned Madiun and spacing $2 \mathrm{~m} \times 6 \mathrm{~m}$.
\end{abstract}

Key words: Cloned teak, pores, planting distance, Cepu, Madiun

\section{PENDAHULUAN}

Kebutuhan industri kayu jati sebagai bahan baku cenderung terus meningkat dari tahun ke tahun. Kebutuhan tersebut tidak dapat dipenuhi oleh produksi yang ada. Menurut Mahfudz et al., (2007), produksi kayu jati Indonesia hanya 0,8 juta $\mathrm{m} 3 \mathrm{thn}^{-1}$, sedangkan kebutuhan industri mencapai 2,5 juta $\mathrm{m}^{3} \mathrm{thn}^{-1}$. Untuk mengatasi permasalahan tersebut, berbagai upaya telah dilakukan termasuk menerapkan metode propagasi untuk menghasilkan klon-klon jati yang diharapkan memiliki karakter yang sama dengan induknya. Melalui propagasi, daur tanaman jati bisa lebih singkat, dari \pm 60 tahun menjadi \pm 20 tahun untuk kayu pertukangan. Pada kenyataannya, sering dijumpai adanya variasi karakteristik pertumbuhan, baik akibat pengaruh lingkungan (perbedaan jarak tanam, tempat tumbuh, kelerengan dan lain-lain) maupun akibat perbedaan genetik (asal klon dan provenansi). Bahkan dalam satu tree plot pun ditemukan adanya variasi pertumbuhan yang cukup signifikan. Variasi karakteristik pertumbuhan tersebut akan

Diterima: 10 Mei 2012; Disetujui: 18 Juli 2012

$\square$ Penulis korespondensi (corresponding author): detti_yunianti@yahoo.com memengaruhi karakteristik dan kualitas kayu yang akan dihasilkan. Hal ini menimbulkan pertanyaan, apakah pembentukan sel-sel di dalam pohon yang dipercepat sama dengan yang slow growing.

Secara genetik, beberapa sifat khas jati telah dikenal terutama porositasnya yaitu tata lingkar (perbedaan kayu awal dan akhir sangat jelas), tetapi dengan percepatan pertumbuhan kemungkinan terjadi perubahan-perubahan karena anomalianomali perkembangan sel. Perubahan porositas akan memengaruhi sifat-sifat kayu lainnya, terkait dengan proporsi kayu awal dan kayu akhir antara lain yaitu dimensi pembuluh. Parameter kualitas kayu seperti berat jenis dan kerapatan kayu, serta dimensi serat sangat dipengaruhi oleh proporsi kayu awal dan kayu akhir. Oleh karena itu, penelitian ini dilakukan untuk mengetahui fenomena perubahan porositas dan dimensi pembuluh pada kayu jati yang berasal dari klon pada jarak tanam yang berbeda.

\section{METODE PENELITIAN}

\section{Persiapan Bahan}

Pohon jati umur 7 tahun berasal dari Hutan Penelitian Watu Sipat milik Balai Besar Penelitian Bioteknologi dan Pemuliaan Tanaman Hutan 


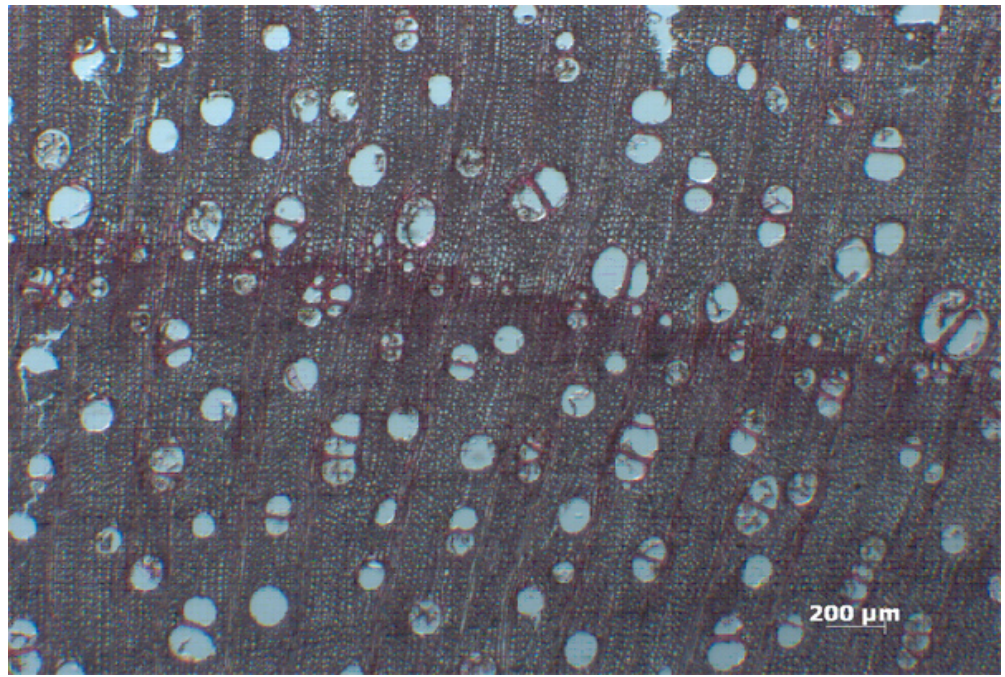

Gambar 1. Porositas tata baur pada lingkaran tahun pertama

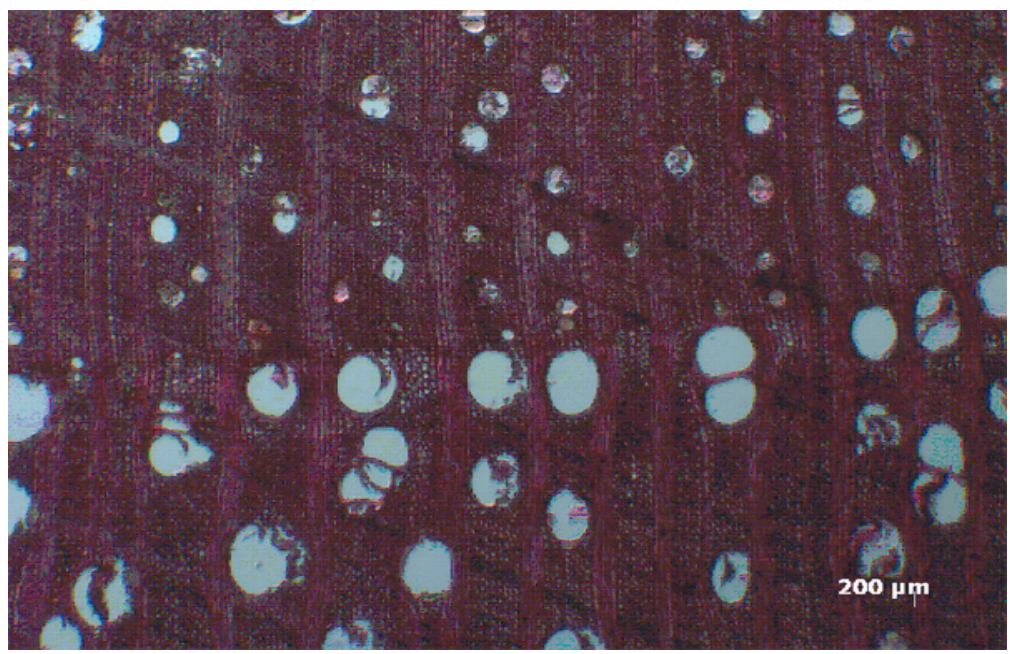

Gambar 2. Porositas semi-tata baur pada lingkaran tahun kelima

(B2PBPTH), Kementerian Kehutanan, khususnya pada petak 22a, RPH Banaran, BKPH Playen, Gunung Kidul, Yogyakarta. Pohon penelitian berasal dari 2 klon Cepu dan 1 klon Madiun pada masing-masing jarak tanam $(3 \mathrm{~m} \times 3 \mathrm{~m}$ dan $2 \mathrm{~m}$ $x 6 \mathrm{~m}$ ). Bagian pohon yang diambil sebagai bahan penelitian adalah lempengan setebal $5 \mathrm{~cm}$ pada ketinggian $50 \mathrm{~cm}$ dari permukaan tanah.

\section{Metode}

Porositas setiap lempengan yang menjadi contoh uji diamati per riap tumbuh dari hasil sayatan, sementara dimensi dan frekuensi pembuluh diukur berdasarkan Wheeleretal.(1989)darihasil maserasi. Porositas, dimensi dan frekuensi pembuluh dari klon Cepu dan klon Madiun diproyeksikan dengan mikroskop mikro Axio Imager.

\section{HASIL DAN PEMBAHASAN}

Secara genetik kayu jati termasuk kayu yang memiliki porositas kayu berpori tata lingkar yaitu kayu yang pembuluh pada kayu awalnya sangat berbeda dengan pembuluh kayu akhirnya. Menurut Martawijaya et al. (2005), pori kayu jati sebagian besar atau hampir seluruhnya soliter dalam susunan tata lingkar. Kayu jati memiliki bentuk porositas tata lingkar karena sifatnya yang deciduous tree (kayu yang menggugurkan daun pada musim kemarau untuk mengurangi kebutuhan air).

Hasil penelitian ini menunjukkan bahwa porositas kayu jati, baik yang berasal dari klon Cepu maupun klon Madiun pada tiga tahun pertama memiliki porositas tata baur kemudian berangsurangsur menjadi semi tata lingkar pada tahun 


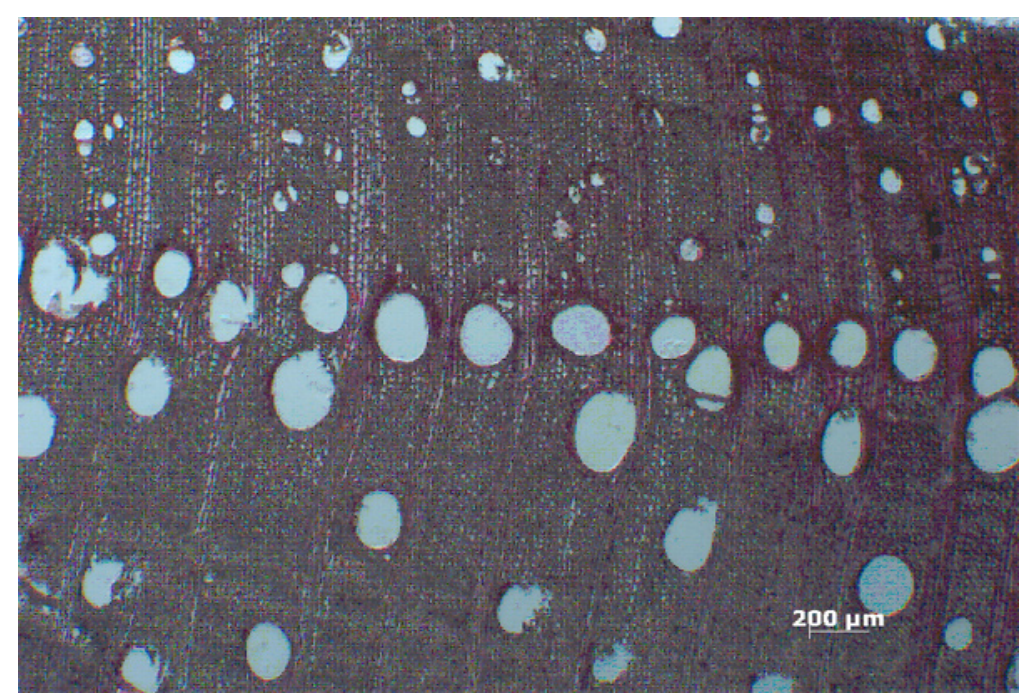

Gambar 3. Porositas tata lingkar pada lingkaran tahun keenam

keempat sampai kelima/enam (Gambar 1, 2 dan 3).

Menurut Wheeler et al. (1989), porositas pada daerah yang basah (memiliki curah hujan yang tinggi) cenderung semi tata baur sementara daerah yang kering (memiliki curah hujan yang rendah) cenderung tata baur. Sementara hasil penelitian dari Nobuchi et al. (2005) menunjukkan bahwa tanaman jati yang berasal dari Cepu (daerah kering) memiliki porositas tata baur dibandingkan tanaman jati yang berasal dari Sukabumi (daerah basah) memiliki porositas semi tata baur. Menurut Anonim (2003), hutan penelitian Watu Sipat memiliki iklim tipe D dengan curah hujan berkisar 16,55-42,52 $\mathrm{mm}$ atau termasuk daerah yang kering.
Faktor lingkungan dapat mengubah porositas tanaman jati menjadi tata baur walaupun secara genetik memiliki porositas tata lingkar. Percepatan pertumbuhan dari klon-klon pada tegakan jati di awal pertumbuhan dengan pemberian pupuk di lapangan membuat pertumbuhan sel-sel pada awal pertumbuhan sangat pesat sehingga terbentuk porositas tata baur pada tahun pertama sampai ketiga. Selanjutnya porositas berangsurangsur menjadi semi tata lingkar atau tata lingkar. Perubahan porositas dapat memengaruhi sifat dasar lainnya seperti berat jenis (BJ) dan kerapatan kayu. Perubahan ini bisa disebabkan oleh dimensi dan frekuensi pembuluh. Sel pembuluh memiliki dinding sel yang tipis sehingga jumlah pembuluh

Tabel 1. Dimensi dan Frekuensi Pembuluh Klon Cepu and Klon Madiun

\begin{tabular}{|c|c|c|c|c|c|c|c|}
\hline \multirow{2}{*}{ Jarak Tanam } & \multicolumn{6}{|c|}{ Sumber } & \multirow{2}{*}{ Rata-rata } \\
\hline & $\mathrm{n}$ & Biji & $\mathrm{n}$ & Klon Cepu & $\mathrm{n}$ & Klon Madiun & \\
\hline \multicolumn{8}{|c|}{----- Panjang Pembuluh $(\mu \mathrm{m})$----- } \\
\hline $3 \mathrm{~m} \times 3 \mathrm{~m}$ & 1 & $334,73 \pm 21,62$ & 6 & $355,87 \pm 10,96$ & 3 & $357,42 \pm 5,93$ & 355,87 \\
\hline $2 \mathrm{~m} \times 6 \mathrm{~m}$ & 1 & & 6 & $357,72 \pm 25,62$ & 3 & $367,60 \pm 28,91$ & 362,66 \\
\hline Rata-rata & & & & 356,80 & & 362,51 & \\
\hline \multicolumn{8}{|c|}{ ensial Pembuluh ( } \\
\hline $3 \mathrm{~m} \times 3 \mathrm{~m}$ & 1 & $177,43 \pm 20,99$ & 6 & $173,96 \pm 24,05$ & 3 & $180,40 \pm 7,09$ & 173,96 \\
\hline $2 m \times 6 m$ & 1 & & 6 & $183,72 \pm 24,39$ & 3 & $174,81 \pm 12,71$ & 179,26 \\
\hline Rata-rata & \multicolumn{6}{|c|}{178,84} & \\
\hline \multicolumn{8}{|c|}{---- Frekuensi Pembuluh $\left(\mathrm{mm}^{-2}\right)$----- } \\
\hline $3 \mathrm{~m} \times 3 \mathrm{~m}$ & 1 & 19,13 & 6 & 20,84 & 3 & 23,46 & 22,15 \\
\hline $2 m \times 6 m$ & 1 & & 6 & 20,71 & 3 & 22,90 & 21,81 \\
\hline Rata-rata & & & & 20,78 & & 23,18 & \\
\hline
\end{tabular}


yang banyak per satuan luas dengan diameter yang besar akan menurunkan BJ dan kerapatan kayu. Hal ini menyebabkan kekuatan kayu menjadi menurun.

Dimensi dan frekuensi pembuluh tanaman jati yang berasal dari klon Cepu dan klon Madiun pada jarak tanam $3 \mathrm{~m} \times 3 \mathrm{~m}$ dan $2 \mathrm{~m} \times 6 \mathrm{~m}$ sebagaimana disajikan pada Tabel 1. Tabel 1 menunjukkan bahwa dimensi pembuluh pada jarak tanam yang lebar memiliki diameter dan panjang pembuluh lebih besar dengan frekuensi yang rendah dibandingkan pada jarak tanam yang kecil. Pada jarak tanam $2 \mathrm{~m}$ $\mathrm{x} 6 \mathrm{~m}$ riap pertumbuhan diameter thn ${ }^{-1}$ lebih besar $(1,87 \mathrm{~cm}$ thn-1 $)$ dibandingkan dengan jarak tanam 3 $\mathrm{m} \times 3 \mathrm{~m}\left(1,70 \mathrm{~cm} \mathrm{thn}^{-1}\right)$. Makin cepat pertumbuhan makin besar diameter pembuluh yang terbentuk, yang menyebabkan BJ dan kerapatan kayu pada jarak tanam $2 \mathrm{~m} \times 6 \mathrm{~m}$ lebih rendah (0,55 dan 0,64 $\mathrm{g} \mathrm{cm}^{-3}$ ) dibandingkan dengan jarak tanam $3 \mathrm{~m} \times 3 \mathrm{~m}$ $\left(0,57\right.$ dan $\left.0,67 \mathrm{~g} \mathrm{~cm}^{-3}\right)$.

Interval dimensi dan jumlah pembuluh per $\mathrm{mm}$ pada jarak tanam $3 \mathrm{~m} \times 3 \mathrm{~m}$ lebih kecil dibandingkan dengan jarak tanam $2 \mathrm{~m} \times 6 \mathrm{~m}$, yang menandakan sebaran pembuluh pada jarak tanam yang sempit dan seimbang lebih kecil dibandingkan dengan jarak tanam yang lebar dan tidak seimbang. Pada jarak tanam $3 \mathrm{~m} \times 3 \mathrm{~m}$, memiliki panjang dan diameter pembuluh yang kecil dengan jumlah per satuan luas lebih banyak.

Panjang dan jumlah pembuluh per mm pada klon Cepu lebih kecil dibandingkan klon Madiun, tetapi sebaliknya untuk diameter pembuluh. Interval dimensi dan jumlah pembuluh per mm pada klon Cepu lebih kecil dibandingkan dengan klon Madiun, yang menandakan sebaran pembuluh klon Cepu lebih seragam dibandingkan dengan klon Madiun. Keseragaman dimensi pembuluh terutama diameter pembuluh, erat hubungannya dengan proporsi pembuluh di dalam kayu, hal ini berkaitan dengan BJ dan kerapatan kayu. Klon Cepu memiliki BJ dan kerapatan kayu yang lebih tinggi $(0,57$ dan $0,66 \mathrm{~g}$ $\mathrm{cm}^{-3}$ ) dibandingkan dengan klon Madiun (0,54 dan $0,63 \mathrm{~g} \mathrm{~cm}^{-3}$ ). Makin banyak sel pembuluh yang memiliki diameter yang besar, makin rendah BJ dan kerapatan suatu kayu.
Karakteristik kayu yang berubah akan memengaruhi produk akhir dari suatu tegakan, sehingga informasi fenomena perubahan kualitas kayu pada jenis-jenis yang dipercepat pertumbuhannya, sangat diperlukan untuk melakukan tindakan silvikulturyang tepat. Disamping itu, pemuliaan pohon dalam menghasilkan jenisjenis klon yang terbaik perlu informasi dasar mengenai kualitas kayu. Secara berkelanjutan akan terus dikembangkan jenis-jenis yang terbaik secara genotipe maupun fenotipe. Hal ini diharapkan dapat mendukung program clonal forestry.

\section{KESIMPULAN}

Perubahan porositas kayu jati yang dipercepat pertumbuhannya dari tata baur menjadi tata lingkar terjadi setelah tanaman jati berumur 3 tahun. Jarak tanam dan asal klon memengaruhi dimensi pembuluh sehingga terdapat perbedaan BJ dan kerapatan kayu jati yang berasal dari klon yang ditanam pada jarak tanam berbeda. Keseragaman dimensi pembuluh terutama diameter pembuluh, erat hubungannya dengan proporsi pembuluh di dalam kayu.

\section{DAFTAR PUSTAKA}

[Anonim]. 2003. Studi Pengembangan Konservasi Wisata Alam Bunder. Laporan Akhir. Kerjasama Fakultas Kehutanan, Universitas Gadjah Mada dan Dinas Kehutanan dan Perkebunan. Daerah Istimewa Yogyakarta.

Mahfudz, M.F., Anis, Yuliah, T. Herawan, Prastyono dan S. Henry. 2007. Sekilas tentang Jati (Tectona grandis). Penyunting: Parwito D dan S. Donie. Pusat Penelitian dan Pengembangan Bioteknologi dan Pemuliaan Tanaman Hutan. Yogyakarta.

Martawijaya, A., I. Kartasujana, K. Kadir dan S.A. Prawira. 2005. Atlas Kayu Indonesia. Jilid I. Departemen Kehutanan. Badan Penelitian dan Pengembangan Kehutanan. Bogor.

Nobuchi, T., Y. Higashikawa and T.L. Tobing. 2005. Some Characteristics of Growth Ring Structure and Heartwood of Teak (Tectona grandis). 76: 33-38.

Wheeler, E.A., P. Baas and P.E. Gasson. 1989. IAWA List of Microcopic Features for Hardwood Identification. IAWA Bulletin n.s. 10(3):219-332. 